\title{
Primary Post-Partum Haemorrhage Following Vaginal Deliveries at the Douala General Hospital: Prevalence, Causes and Risk Factors
}

\author{
Théophile Njamen Nana ${ }^{1,2}$, Robert Tchounzou ${ }^{2 *}$, Fulbert Nkwele Mangala ${ }^{1,3}$, Henri Essome ${ }^{3}$, \\ Javorez Thibaut Demgne ${ }^{4}$, Fidelia Mbi Kobenge1, Bongoe Adamo1, Thomas Obinchemti Egbe1,2, \\ Charlotte Tchente Nguefack ${ }^{1,3}$, Gregory Ekane Halle ${ }^{1,2}$
}

\author{
${ }^{1}$ Department of Obstetrics and Gynecology, Douala General Hospital, Douala, Cameroon \\ ${ }^{2}$ Department of Obstetrics and Gynecology, Faculty of Health Sciences, University of Buea, Buea, Cameroon \\ ${ }^{3}$ Department of Surgery and Specialities, Faculty of Medicine and Pharmaceutical Sciences, University of Douala, Douala, Cameroon \\ ${ }^{4}$ Institut Supérieur des Sciences de la Santé, Université des Montagnes, Bangangte, Cameroun \\ Email: *rtchounzou@yahoo.fr
}

How to cite this paper: Nana, T.N., Tchounzou, R., Mangala, F.N., Essome, H., Demgne, J.T., Kobenge, F.M., Adamo, B., Egbe. T.O., Nguefack, C.T. and Halle, G.E. (2021) Primary Post-Partum Haemorrhage Following Vaginal Deliveries at the Douala General Hospital: Prevalence, Causes and Risk Factors. Open Journal of Obstetrics and Gynecology, 11, 742-752. https://doi.org/10.4236/ojog.2021.116069

Received: April 14, 2021

Accepted: June 15, 2021

Published: June 18, 2021

Copyright (c) 2021 by author(s) and Scientific Research Publishing Inc. This work is licensed under the Creative Commons Attribution International License (CC BY 4.0).

http://creativecommons.org/licenses/by/4.0/ (c) (i) Open Access

\begin{abstract}
Background: Postpartum haemorrhage is one of the leading causes of maternal morbidity and mortality worldwide. It occurs predominantly in developing countries due to poorly developed infrastructures and lack of skilled birth attendants. Objective: To identify the prevalence, causes and risk factors of primary postpartum haemorrhage following vaginal deliveries in a referral hospital (Douala General Hospital-Cameroon). Methods: This was a descriptive and analytical study carried in the Douala General Hospital (DGH) for which socio-demographic, clinical, obstetric and post-partum data were collected using a pre-tested questionnaire. Descriptive statistics, multivariate analysis and logistic regression allowed us to present and discuss our results, with a $95 \%$ confidence interval (CI) and $p$ value $<0.05$. Results: The prevalence of Primary Postpartum Haemorrhage was 1.33\%. Quantification of bleeding was reported in only $13.15 \%$ of cases. The main causes were: uterine atony $(36.18 \%)$, placental retention $(25.65 \%)$, cervical tears $(12.50 \%)$, perineal tears $(10.52 \%)$ and cervico-vaginal tears $(08.52 \%)$. The risk factors were: age between $19-35$ years $\mathrm{aOR}=4.52 ; 95 \% \mathrm{CI}=2.65-7.98 ; p=0.021)$; unemployment $(\mathrm{aOR}=4.74 ; 95 \% \mathrm{CI}=2.91-6.02 ; p=0.001)$; being multigravida $(\mathrm{aOR}=9.21 ; 95 \% \mathrm{CI}=6.43-12.48 ; p=0.035)$; history of abortion $(\mathrm{aOR}=5.11 ; 95 \% \mathrm{CI}=2.05-7.29 ; p=0.004)$; preterm delivery $(\mathrm{aOR}=6.88$; $95 \% \mathrm{CI}=2.72-9.06 ; p=0.002)$; duration of labour $>12$ hours $(\mathrm{aOR}=4.05$; $95 \% \mathrm{CI}=2.46-7.98 ; p=0.003)$ and macrosomia $(\mathrm{aOR}=3.27 ; 95 \% \mathrm{CI}=1.03$ - 5.68; $p=0.041$ ). Conclusion: Primary postpartum haemorrhage remains a poorly assessed obstetric complication in the maternity ward of the Douala
\end{abstract}


General Hospital (DGH); Training staff on quantifying postpartum blood loss and monitoring the second and third stages of labour can help to better manage and reduce its occurrence.

\section{Keywords}

Primary Postpartum Haemorrhage, Prevalence, Causes, Risk Factors

\section{Introduction}

The World Health Organization (WHO) defines Primary Postpartum Haemorrhage (PPH) as blood loss of at least $500 \mathrm{ml}$ occurring within 24 hours of childbirth [1]. Postpartum haemorrhage is a combination of bleeding from delivery and haemorrhage from the birth canal. It concerns $5 \%$ of deliveries [2]. PPH is the leading cause of maternal mortality in low-income countries and the leading cause of nearly one in four maternal deaths worldwide [1]. In 2015, according to the WHO, around 830 women died every day around the world due to complications related to pregnancy or childbirth and nearly 300,000 women died during pregnancy, childbirth or in the days that followed [3]. Despite the progress made in the management of $\mathrm{PPH}$, it remains an important factor in maternal morbidity and mortality, in both developing and developed countries [4] [5]. In Cameroon, the maternal mortality rate increased from 484 deaths in 1998, to 669 deaths in 2004, then to 690 deaths in 2010 and to 789 deaths in 2014 per 100,000 live births, the main cause of which was PPH secondary to uterine atony [6] [7] and [8]. The high death rates, despite the management policies in place, illustrate the public health problem of $\mathrm{PPH}$ in our context. We designed this study with the aim of appreciating the magnitude of the problem at the Douala General Hospital (DGH), which is a tertiary level health facility that must provide quality care, in order to identify efficient corrective measures.

\section{Methods}

\subsection{Study Design and Site}

This was a descriptive and case-control study of all vaginal deliveries complicated by primary postpartum haemorrhage $(\mathrm{PPH})$ that occurred between January 1, 2009 and December 31, 2018 in the obstetrics department of the DGH. The DGH is one of the tertiary level referral hospitals in Cameroon, which has a capacity of 320 beds distributed in different departments and units. The Gynaecology and obstetrics department has an operating theatre, a maternity ward and hospitalisation wards coordinated by obstetricians and gynaecologists, and midwives. Obstetric emergencies like PPH are managed following guidelines developed by the administration of the service.

\subsection{Inclusion Criteria}

Cases were files of patients who delivered at a gestational age of 28 weeks and 
more, and had post partum blood loss in excess of $500 \mathrm{ml}$ when blood loss was quantified or any those with hemodynamic instability, pre-shock, or hypovolemic shock due to profuse bleeding.

Controls were constituted by files of women who had vaginal delivery with no post partum haemorrhage within the first 24 hours following delivery.

Cases and controls were matched for age in years, the year and month of occurrence of PPH. We matched 1 case to 3 controls.

\subsection{Exclusion Criteria}

We excluded:

- All files with less than $25 \%$ of required information;

- Cases of caesarean section and;

- Secondary post partum haemorrhage, occurring more than 24 hours after delivery.

\subsection{Sample Size}

We used a consecutive and convenience sampling. The minimum sample size was calculated from Schesselman's formula [9].

$$
n=\left(\frac{r+1}{r}\right) \frac{(p)(1-p)(z \partial+z \beta)^{2}}{\left(p_{1}-p_{2}\right)^{2}}
$$

$n=$ minimum sample size;

$r=$ case/control ratio (number of controls is equal to 03 times the number of cases) $=1 / 3$;

$P_{1}=$ proportion of the main factor in the group of cases [10];

$P_{2}=$ proportion of the main factor in the control group [10];

$P=\left(p_{1}+p_{2}\right) / 2=$ mean of the proportions;

$P_{1}-p_{2}=$ difference in proportions;

$Z \alpha=$ standardized level of significance $=1.96$

$Z \beta=$ standardized power $=0.84$;

$$
n=\left(\frac{\frac{1}{3}+1}{\frac{1}{3}}\right) \frac{(0.366)(1-0.366)(1.96+0.84)}{(0.134-0.5)^{2}}=85.683 \approx 86
$$

$n=86$ cases for 258 controls or a total of 344 files with 1 case for 3 controls.

\subsection{Data Processing and Analysis}

Childbirth registers, hospitalization records and medical records were used to collect the data. The socio-demographic variables, the clinical profile and the characteristics related to pregnancy and childbirth were analysed with the SPSS 20.0 software. The odds ratio (OR) at 95\% confidence interval (CI) allowed to measure the association between the dependent and independent qualitative variables. The logistic regression eliminated the confounding factors and the error threshold p was set at 0.05 . 


\subsection{Ethical Considerations}

Ethical clearance was obtained from the ethics committee of the Universite des Montagnes. Authorization was obtained from the administration of the Douala General Hospital. The principles of research ethics were observed during the study.

\section{Results}

We compiled a number of 163 cases of PPH but only 152 were included in the study; 4 files had incomplete data and 7 were not found. Controls were constituted by 456 files.

\subsection{Prevalence of Post-Partum Haemorrhage}

We recruited 12,240 deliveries during our study period with 163 cases of $\mathrm{PPH}$, giving a prevalence of $1.33 \%$. Eleven files were excluded: 04 with incomplete data and 07 not found. We worked on a total of 608 files, 152 for the cases and 456 for the controls.

\subsection{Causes of Post-Partum Haemorrhage}

The quantification of bleeding was mentioned in 20/152 files, (13.15\%). The remaining (86.5\%) was clinical and visual assessment.

As shown in Table 1, the causes of PPH at DGH were classified in two groups: haemorrhage during delivery which occurred in 95 cases $(62.50 \%)$ of which uterine atony represented 55 cases $(36.18 \%)$ and placental retention which occurred in 39 cases $(25.65 \%)$ and uterine inversion 1 case $(0.65 \%)$; the second group was genital tract lacerations which occurred in 57 cases (37.50\%) among which: 19 cases $(12.50 \%)$ of cervical tears, 16 cases $(10.52 \%)$ of perineal tears, 13 cases $(8.55 \%)$ of cervico-vaginal tears, 7 cases of uterine rupture $(4.60 \%)$ and 2 cases of perineal and pelvic haematomas (1.31\%).

Table 1. Distribution of cases according to the aetiology of postpartum haemorrhage.

\begin{tabular}{|c|c|c|c|}
\hline Sites & Causes & Frequency (n) & Percentage (\%) \\
\hline Haemorrhage during & Uterineatony & 55 & 36.18 \\
\hline \multirow[t]{4}{*}{ delivery } & Placental retention & 39 & 25.65 \\
\hline & Uterine inversion & 01 & 0.65 \\
\hline & & & 62.50 \\
\hline & Cervical tears & 19 & 12.5 \\
\hline \multirow[t]{6}{*}{ Genital tractlaceratons } & Perineal tears & 16 & 10.52 \\
\hline & Cervico-vaginal tears & 13 & 08.55 \\
\hline & Uterine rupture & 07 & 04.60 \\
\hline & Perineal and pelvic hematomas & 02 & 01.31 \\
\hline & & & 37.50 \\
\hline & TOTAL & 152 & 100.00 \\
\hline
\end{tabular}




\subsection{Risk Factors}

- Sociodemographic characteristics related to postpartum haemorrhage (Table 2).

The mean age of the 152 participants with PPH was $22.4 \pm 4.07$ years. $63.82 \%$ of them were aged between 19 to 35 years. This age group increased the risk of PPH by 3.49 with a significant difference. On the other hand, the age group of less than 19 years multiplied the risk of PPH by 2.7 with a non-significant difference. Being single increased the risk of PPH by 4.36 times with a significant difference. Unemployment increased the risk of PPH by 2.9 times with a significant difference. There was no significant difference regarding religion.

The personal past histories of the participants revealed that (Table 3): Being multigravida increased the risk of PPH by 6.45 times with a significant difference. Being primiparous increased the risk of $\mathrm{PPH}$ by 1.21 with a significant difference. The history of PPH and abortion increased the risk of PPH by 6.97 and 3.56 , respectively, with significant differences. There was no significant difference between the two groups for medical and surgical past histories. Self-medication with traditional oxytocin-like drugs increased the risk of PPH by 2.27 times with a significant difference.

The characteristics of pregnancy and childbirth (Table 4) revealed that there is no association between the occurrence of $\mathrm{PPH}$ and the attendance or not to ANC; preterm delivery ( 28 - 36 weeks +6 days) increased the risk of PPH by 4 with a significant difference. Induction of labour and stimulation were not associated with PPH. The duration of labour ( $>12 \mathrm{~h}$ ) multiplied the risk of PPH by 3.11 with a significant difference. Newborns with a birth weight over $4000 \mathrm{~g}$ had a 4.38-fold increase in risk of PPH with a significant difference.

Table 2. Distribution of cases and controls according to socio-demographic variables.

\begin{tabular}{ccccc}
\hline Variables & $\begin{array}{c}\text { Cases }(\mathrm{N}=152) \\
\mathrm{n}(\%)\end{array}$ & $\begin{array}{c}\text { Controls }(\mathrm{N}=456) \\
\mathbf{n}(\%)\end{array}$ & OR (CI 95\%) & $p$-value \\
\hline Age (years) & & & & \\
$<19$ & $20(13.16)$ & $66(14.47)$ & $2.70(1.59-5.79)$ & 0.13 \\
$19-35$ & $97(63.82)$ & $296(64.91)$ & $3.49(2.00-5.21)$ & 0.04 \\
$>35$ & $35(23.02)$ & $108(23.68)$ & $0.99(0.69-1.73)$ & 0.77 \\
Marital status & & & & \\
Single & $60(39.47)$ & $282(61.84)$ & $4.36(2.73-6.22)$ & $<0.01$ \\
Married/cohabitation & $92(60.53)$ & $188(41.22)$ & $0.59(0.16-2.18)$ & 0.62 \\
Profession & & & & 0.23 \\
Employed & $51(33.56)$ & $114(25.00)$ & $4.41(3.32-6.65)$ & $<0.01$ \\
Unemployed & $101(66.44)$ & $356(78.00)$ & $2.90(1.32-4.72)$ & $<$ \\
Religion & & & & $<0.01$ \\
Christian & $108(71.06)$ & $310(67.98)$ & $0.52(0.36-0.75)$ & $<0.19$ \\
Muslim & $26(17.10)$ & $117(25.65)$ & $0.41(0.24-0.69)$ & $<0.01$ \\
Jehovahwitness & $18(11.84)$ & $43(09.42)$ & $2.64(3.79-8.46)$ & 0.19 \\
\hline
\end{tabular}


Table 3. Distribution of cases and controls according to personal history.

\begin{tabular}{|c|c|c|c|c|}
\hline Variables & $\begin{array}{c}\text { Cases } \\
\mathrm{N}=152 \\
\mathrm{n}(\%)\end{array}$ & $\begin{array}{c}\text { Controls } \\
\mathrm{N}=456 \\
\mathrm{n}(\%)\end{array}$ & OR $(C I=95 \%)$ & $p$-value \\
\hline \multicolumn{5}{|l|}{ Gravidity } \\
\hline Multigravida & $74(48.68)$ & $227(49.78)$ & $6.45(5.27-8.02)$ & 0.04 \\
\hline Paucigravida & $52(34.21)$ & $140(30.70)$ & $0.59(0.41-0.85)$ & $<0.01$ \\
\hline Primigravida & $26(17.11)$ & $103(22.58)$ & $0.46(0.28-0.76)$ & $<0.01$ \\
\hline \multicolumn{5}{|l|}{ Parity } \\
\hline Multipara & $66(43.42)$ & $236(51.75)$ & $1.36(0.01-3.84)$ & 0.65 \\
\hline Paucipara & $50(32.89)$ & $129(28.28)$ & $1.25(0.74-1.47)$ & 0.03 \\
\hline Primipara & $36(23.68)$ & $105(23.02)$ & $1.21(0.87-1.70)$ & $<0.01$ \\
\hline \multicolumn{5}{|c|}{ Obstetric and gynaecological history } \\
\hline History of abortion & $69(45.39)$ & $115(25.21)$ & $3.56(2.75-5.76)$ & $<0.01$ \\
\hline History of $\mathrm{PPH}$ & $1(0.66)$ & $7(01.53)$ & $6.97(4.60-9.20)$ & 0.24 \\
\hline History of hypertension & $03(1.97)$ & $34(07.45)$ & $0.08(0.01-0.62)$ & $<0.01$ \\
\hline History of caesarian section & $20(13.16)$ & $111(24.34)$ & $0,49(0.29-0.82)$ & $<0.01$ \\
\hline Myomectomy & $1(0.66)$ & $26(05.70)$ & $0.11(0.01-0.84)$ & $<0.01$ \\
\hline \multicolumn{5}{|l|}{ Drug history } \\
\hline Traditional uterotonics & $03(1.97)$ & $13(02.85)$ & $2.27(1.40-3.69)$ & $<0.01$ \\
\hline
\end{tabular}

${ }^{*}$ Paucipara here represents women with 2 to 3 deliveries; ${ }^{*}$ Multipara are women with 4 deliveries and more.

Table 4. Characteristics of pregnancy and delivery of cases and controls.

\begin{tabular}{|c|c|c|c|c|}
\hline Variables & $\begin{array}{c}\text { Cases } \\
\mathrm{N}=152 \\
\mathrm{n}(\%)\end{array}$ & $\begin{array}{c}\text { Controls } \\
\mathrm{N}=456 \\
\mathrm{n}(\%)\end{array}$ & OR (CI 95\%) & $p$-value \\
\hline \multicolumn{5}{|l|}{ ANC follow-up (Number of ANC) } \\
\hline None & $15(9.87)$ & $27(05.92)$ & $0.95(0.70-1.30)$ & 0.85 \\
\hline Between 1 and 4 & $100(65.79)$ & $327(71.71)$ & $1.06(0.51-3.94)$ & $<0.01$ \\
\hline Greater than 4 & $37(24.34)$ & $116(25.43)$ & $1.051(0.74-1.47)$ & 0.83 \\
\hline \multicolumn{5}{|l|}{ Gestational age (Weeks) } \\
\hline $28-36$ & $20(13.16)$ & $96(21.05)$ & $4.5(1.61-7.16)$ & 0.02 \\
\hline $37-42$ & $127(83.55)$ & $303(66.44)$ & $1.68(0.14-5.65)$ & 0.13 \\
\hline Greater than 42 & $5(3.29)$ & $71(15.57)$ & $8.28(5.3-8.51)$ & 0.42 \\
\hline Augmentation of labour Yes & $67(44.08)$ & $126(27.63)$ & $0.46(0.31-0.67)$ & $<0.01$ \\
\hline Induction of labour Yes & $02(1.32)$ & $11(02.41)$ & $0.59(0.16-2.18)$ & 0.62 \\
\hline Instrumental extraction Yes & $3(1.97)$ & $9(01.97)$ & $1.03(0.27-3.85)$ & 0.46 \\
\hline \multicolumn{5}{|l|}{ Duration of labour (hours) } \\
\hline$\leq 12$ & $140(86.85)$ & $264(57.89)$ & $0.25(1.05-1.45)$ & 0.12 \\
\hline$>12$ & $12(7.89)$ & $206(45.17)$ & $3.11(2.06-6.43)$ & 0.02 \\
\hline
\end{tabular}




\section{Continued}

\begin{tabular}{ccccc}
\hline AMTSL Yes & $152(100)$ & $450(98.68)$ & $0.64(1.05-2.45)$ & $<0.01$ \\
Episiotomy Yes & $32(21.05)$ & $108(23.68)$ & $0.89(0.57-1.39)$ & 0.31 \\
Birthweigth (grams) & & & & \\
$2500-4000$ & $111(73.03)$ & $287(62.93)$ & $0.14(0.09-0.21)$ & $<0.01$ \\
$<2500$ & $13(8.55)$ & $120(26.31)$ & $0.87(0.16-2.18)$ & $<0.01$ \\
$>4000$ & $28(18.42)$ & $63(13.81)$ & $4.38(2.70-7.27)$ & 0.03 \\
Multiple gestation & $15(9.87)$ & $74(16.22)$ & $0.17(0.06-1.18)$ & 0.32 \\
Hydramnios & $02(0.00)$ & $05(01.09)$ & $2.24(0.09-1.21)$ & 0.50 \\
Myomas in pregnancy & $00(0.00)$ & $02(00.43)$ & $0.76(0.09-2.21)$ & 0.42 \\
\hline
\end{tabular}

The most significant factors after multivariate analysis (Table 5) were: age (19 - 35 years), absence of employment, being multigravida, history of abortion, gestational age between 28 - 36 weeks, duration of labour $>12$ hours and birth weight $>4000 \mathrm{~g}$.

As shown in Table 5, age group of 19 - 35 years, unemployment, multigravidity, history of previous abortion, prematurity, prolonged labour and macrosomia were associated to increased risks of $\mathrm{PPH}$ in multivariate analysis.

\section{Discussion}

Prevalence: Our prevalence is lower than those found by other authors in Africa, Europe and South America [11] [12], and [13]. This could be explained by the use of visual (and not quantitative) estimation of the blood loss that we found in $85.5 \%$ of cases, a source of error linked to the underestimation of cases of PPH not associated with hemodynamic instability. Stafford et al. [14] indicated that a visual assessment underestimates the loss of abundant blood after childbirth. This underestimation could explain the delay in intervention strategies [15].

Causes of Primary Postpartum Haemorrhage. Bleeding from deliveryaccounted for $62.50 \%$ of the aetiologies. Bleeding from delivery remains a major public health problem in Sub Saharan Africa, where it is the leading cause of maternal mortality [16] [17]. The systematic practice of active management of the third stage of labour (AMTSL) may help reduce its frequency: Univariate analysis has identified AMTSL as a protective factor in PPH; however, we did not find it after linear regression. Trauma to the genital tract came second with $38.38 \%$ of cases and could possibly be explained by ineffective monitoring of the second and third stages of labour.

Risk factors: The age range between 19 and 35 was a risk factor. It corresponds to the period when genital activity is the most intense. This result is consistent with those of some authors in Africa and America [18] [19], and [20]. However, Tsu et al. in Zimbabwe and Henri et al. in Cameroon had found age above 35 years and age below 20 years respectively as risk factors for postpartum haemorrhage [21] [22]. Unemployment increased the risk of PPH 4.74 times: Thomas 
Table 5. Multivariate analysis.

\begin{tabular}{cccc}
\hline Variables & aOR & (CI 95\%) & $p$-value \\
\hline 19 - 35 years & 4.52 & $(2.65-7.98)$ & $\mathbf{0 . 0 2 1}$ \\
Single & 2.18 & $(1.34-5.33)$ & 0.317 \\
Unemployed & 4.74 & $(2.91-6.02)$ & $\mathbf{0 . 0 0 1}$ \\
Multigravida & 9.21 & $(6.43-12.38)$ & $\mathbf{0 . 0 3 5}$ \\
Primiparity & 3.02 & $(0.25-3.39)$ & 0.162 \\
History of abortion & 5.11 & $(2.05-7.29)$ & $\mathbf{0 . 0 0 4}$ \\
Traditional uterotonics & 3.27 & $(2.01-6.91)$ & 0.081 \\
Number of ANC $(1-4)$ & 2.41 & $(1.19-4.40)$ & 0.579 \\
Gestational age $(28-36 \mathrm{Weeks})$ & 6.88 & $(2.72-9.06)$ & $\mathbf{0 . 0 0 2}$ \\
Duration of labour $(>12 \mathrm{~h})$ & 4.05 & $(2.46-7.98)$ & $\mathbf{0 . 0 0 3}$ \\
Birth weigth $(>4000 \mathrm{~g})$ & 3.27 & $(1.03-5.68)$ & $\mathbf{0 . 0 4 1}$ \\
\hline
\end{tabular}

aOR: adjusted Odds Ratio.

et al. also found this factor to be associated with PPH in Sudan [18]. We can hypothesize that the absence of a job decreases their purchasing power, hence the absence/irregularity of antenatal consultations (ANC), or even the inability to pay the costs of the ANC-related check-ups. Being a multigravida has also been reported in Africa and South America as a risk factor for postpartum haemorrhage [5] [18], and [23]. This could be explained by an incomplete coverage of family planning activities for the spacing of pregnancies [24]. A history of previous abortion was found by Obossou et al. in Benin and Henri et al. in Cameroon [22]. In our study, the use of the curette was found in $72.4 \%$ of patients: destruction of the uterine mucosa by the curette can lead to partial adhesion or incomplete detachment of the placenta, thereby exposing to postpartum haemorrhage [25]. We agreed with other authors that preterm delivery was a risk factor for postpartum haemorrhage [26] [27], and [28]. Prematurity is highly susceptible to lead to retention of the placenta, complicated by bleeding at delivery [29]. Labour lasting more than $12 \mathrm{~h}$ was associated with postpartum haemorrhage. Several studies had reached the same conclusion [19] [21] [30], and [31]. An abnormally long duration of labour increases the risk of uterine atony. Birth weight greater than $4000 \mathrm{~g}$ was a risk factor for postpartum haemorrhage in our study. A few authors had also found this association [5] [23], and [32]. This could be explained by the overstretching of the uterus induced by the volume of the foetus, thus promoting uterine atony after childbirth.

\section{Conclusion}

The prevalence of primary postpartum haemorrhage at the DGH is believed to be lower due to the predominantly visual estimate of postpartum bleeding. Enhancing the capacity of maternity staff at the HGD on quantifying postpartum bleeding, monitoring the second and third phase of labour and taking into ac- 
count the risk factors identified will help to better assess and reduce the prevalence of PPH.

\section{Study Limitations}

This study was a retrospective study with the weakness of poor data recording. Besides blood loss was not quantified in the vast majority of cases and when it was, visual estimation used, this is a potential source of error due to underestimation of blood loss and thus a bias on the real prevalence of PPH.

\section{Authors' Contribution}

T. Nana Njamen, R. Tchounzou, F. Nkwele Mangala designed the manuscript, participated in recruitment and wrote the manuscript. All the other authors participated in manuscript revision. All the authors read and approved the final version of the manuscript.

\section{Conflicts of Interest}

All authors of this manuscript declare no competing interests.

\section{References}

[1] Organisation Mondiale de la Santé (2012) Recommandations de l'OMS pour la prévention et le traitement de l'hémorragie du post-partum. OMS, Genève.

[2] Deneux, T.C., Bonnet, M.-P. and Tort, J. (2014) Épidémiologie de l'hémorragie du post-partum. The Journal de Gynécologie Obstétrique et Biologie de la Reproduction, 43, 936-950. https://doi.org/10.1016/j.jgyn.2014.09.023

[3] Organisation Mondiale de la Santé (2015) Mortalité maternelle. OMS, Genève.

[4] Kebede, B.A., Abdo, R.A., Anshebo, A.A. and Gebremariam, B.M. (2019) Prevalence and Predictors of Primary Postpartum Hemorrhage: An Implication for Designing Effective Intervention at Selected Hospitals, Southern Ethiopia. PLoS ONE, 14, e224579. https://doi.org/10.1371/journal.pone.0224579

[5] Omonge, S., Mirembe, F., Wandabwa, J., et al. (2016) Incidence and Risk Factors for Postpartum Hemorrhage in Uganda. Reproductive Health, 13, 38.

https://doi.org/10.1186/s12978-016-0154-8

[6] Fotso, M., René, N., Paul, R.-L., Martin, T., Roger, W., Aboubakar, G., et al. (1999) Enquête Démographique et de Santé (EDS), Cameroun 1998. Bureau Central des Recensements et des Études de Population et Macro International Inc., Calverton.

[7] Institut National de la Statistique (INS) et ORC Macro (2004) Enquête Démographique et de Santé du Cameroun (EDS) 2004. INS et ORC Macro, Calverton.

[8] Institut National de la Statistique (INS) (2015) Enquête Démographique et de Santé et l'enquête par grappes à indicateurs multiples (EDS-MICS5) 2014, Rapport Final. Yaoundé, Institut National de la Statistique.

[9] Schlesselman, J. (1974) Sample Size Requirements in Case-Control Studies of Disease. American Journal of Epidemiology, 99, 381-384. https://doi.org/10.1093/oxfordjournals.aje.a121625

[10] Magnann, E.F., Evans, S., Hutchinson, M., Collins, R., Howard, B.C. and Morrison, J.C. (2005) Postpartum Hemorrhage after Vaginal Birth: An Analysis of Risk Fac- 
tors. Southern Medical Journal, 98, 419-422. https://doi.org/10.1097/01.SMJ.0000152760.34443.86

[11] Kinikanwo, I.G., John, D.O. and Mmom, C.F. (2015) Primary Postpartum Haemorrhage at the University of Port Harcourt Teaching Hospital: Prevalence and Risk Factors. Nigerian Health Journal, 15, 7 p.

[12] Téguété, I., Sissoko, A., Djiré, M., Traoré, Y., Kayentao, K., Théra, T., et al. (2014) Hémorragies du post partum au Mali: fréquences, causes, facteurs de risque et pronostic. CNGOF. 38ème journées nationales. Paris.

[13] Maiga, S.I. (2009) Hémorragie du post-partum immédiat au centre de sante de référence de la Commune I du district de Bamako. Thèse Doctorat, Université de Bamako, Bamako, 125 p.

[14] Stafford, I., Dildy, G.A., Clark, S.L. and Belfort, M.A. (2008) Visually Estimated and Calculated Blood Loss in Vaginal and Cesarean Delivery. American Journal of $\mathrm{Ob}$ stetrics and Gynecology, 199, 519.e1-7. https://doi.org/10.1016/j.ajog.2008.04.049.

[15] Dalaba, M.A., Akweongo, P., Aborigo, R.A., Saronga, H.P., Williams, J., Aninanya, G.A., et al. (2015) Cost to Households in Treating Maternal Complications in Northern Ghana: A Cross Sectional Study. BMC Health Services Research, 15, 34. https://doi.org/10.1186/s12913-014-0659-1

[16] Tebeu, P.M., Halle, E.G., Itambi, M.D., Mbu, R.E., Mawamba, Y. and Fomulu, J.N. (2015) Maternal Mortality in Cameroon: A University Teaching Hospital Report. The Pan African Medical Journal, 21, 16.

[17] Nem, T.D. (2004) Etude de la mortalité maternelle au centre de santé de référence de la commune V de Bamako de 1998 à 2002 à propos de 160 cas. Thèse Doctorat, Université de Bamako, Bamako, 27-77.

[18] Thomas, T.A., Jared, O.O., Mathias, O. and Erneo, B.O. (2014) Risk Factors Associated with Post-Partum Hemorrhage at Juba Teaching Hospital, South Sudan, 2011. South Sudan Medical Journal, 7, 24.

[19] Valdes, V., Adongo, P.B., Nwameme, A.U., Tabong, P.T.N. and Fernandes, M. (2018) Risk Factors for Self Reported Postpartum Hemorrhage in Ga East, Ghana. International Journal of Gynecology \& Obstetrics, 142, 201-206. https://doi.org/10.1002/ijgo.12523.

[20] Sheldon, W.R., Blum, J., Vogel, J.P., Souza, J., Gülmezoglu, A.M. and Winikoff, B. (2014) Postpartum Hemorrhage Management, Risks, and Maternal Outcomes: Findings from the World Health Organization (WHO) Multicountry Survey on Maternal and Newborn Health. British Journal of Obstetrics and Gynaecology, 121, 5-13. https://doi.org/10.1111/1471-0528.12636

[21] Tsu, V.D. (1993) Postpartum Hemorrhage in Zimbabwe: A Risk Factor Analysis. British Journal of Obstetrics and Gynaecology, 100, 327. https://doi.org/10.1111/j.1471-0528.1993.tb12974.x

[22] Henri, M.D. (2013-2014) Facteurs de risque des hémorragies du post-partum à Yaoundé: Etude transversale analytique. Thèse Doctorat, Faculté de Médecine et des Sciences Biomédicales, Université de Yaoundé I, Yaoundé, 112.

[23] Claudio, G., Fernando, A., José, M.B. and Pierre, B. (2009) Risk Factors for Postpartum Hemorrhage in Vaginal Deliveries in a Latin-American Population. Obstetrics \& Gynecology, 113, 1313-1319.

[24] Institut National de la Statistique (INS) (2015) Enquête Démographique et de Santé et l'enquête par grappes à indicateurs multiples (EDS-MICS5), 2014, Rapport Final. Institut National de la Statistique, Yaoundé. 
[25] Merger, R., Moure, J., Levy, J. and Melchior, J. (2001) Précis d'obstétrique. 6th Edition, Masson, Paris, 583.

[26] Reyal, F., Deffarges, J., Luton, D., Blot, P., Oury, J.-F. and Sibony, O. (2002) Hémorragie grave du postpartum. The Journal de Gynécologie Obstétrique et Biologie de la Reproduction, 31, 358-364.

[27] Marocchini, M., Lauféron, J., Quantin, C. and Sagot, P. (2017) Postpartum Hemorrhage with Transfusion: Trends, near Misses, Risk Factors and Management at the Scale of a Perinatal Network. The Journal de Gynécologie Obstétrique et Biologie de la Reproduction, 46, 455-460. https://doi.org/10.1016/j.jogoh.2017.03.011

[28] Valery, S., Picone, O., Coatantiec, Y., Frati, A., Labrousse, C. and Ayoubi, J.-M. (2015) Prématurité modérée 34-37 SA: Description des causes et conséquences néonatales immédiates dans une maternité de niveau 2. Gynécologie Obstétrique \& Fertilité, 43, 582-587. https://doi.org/10.1016/j.gyobfe.2015.06.009

[29] Loaléneur, M. (2018) Impact de l'accouchement prématuré sur la survenue de l'hémorragie du postpartum immédiat. Étude cas-témoins nichée au sein de la cohorte monocentrique brestoise HPP-IPF. Sciences du Vivant [q-bio].

[30] Obossou, A., Salifou, K., Hounkpatin, B., Sidi, I., Hounkponou, A., Houngbo, O., et al. (2015) Risk Factors for Immediate Postpartum Hemorrhages in the Maternity of the University Teaching Hospital of Parakou. Gynecology and Obstetrics (Sunnyvale), 5,7 .

[31] Tessier, V. and Pierre, F. (2004) Facteurs de risques au cours du travail et prévention clinique et pharmacologique de l'hémorragie du post-partum. Journal de Gynécologie Obstétrique et Biologie de la Reproduction, 8, 29-56. https://doi.org/10.1016/S0368-2315(04)96646-X

[32] Dupont, C., Rudigoz, R.C., Cortet, M., Touzet, S., Colin, C., Rabilloud, M., et al. (2014) Incidence, étiologies et facteurs de risque de l'hémorragie du post-partum: Étude en population dans 106 maternités françaises. Journal de Gynécologie Obstétrique et Biologie de la Reproduction, 43, 244-253.

https://doi.org/10.1016/j.jgyn.2013.05.003 